\title{
Platinum reward for theft, or the percutaneous treatment of coronary steal due to a giant coronary artery fistula
}

\author{
Diego Arroyo, Stéphane Cook \\ Department of Cardiology, Hôpital Cantonal de Fribourg, Switzerland
}

\section{Case report}

An 89-year-old sister who presented with angina pectoris and signs of acute left ventricular failure had a history of chronic dyspnoea aggravated a few days prior

\section{Figure 1}

RAO (A) and anteroposterior (B) caudal views.

$L M=$ left main coronary artery; $L A D=$ left anterior descending artery; $L C X=$ left circumflex artery; $\mathrm{B}=$ body of the giant fistula; $\mathrm{C}=$ collet of aneurysmal formation before reaching the right atrium.
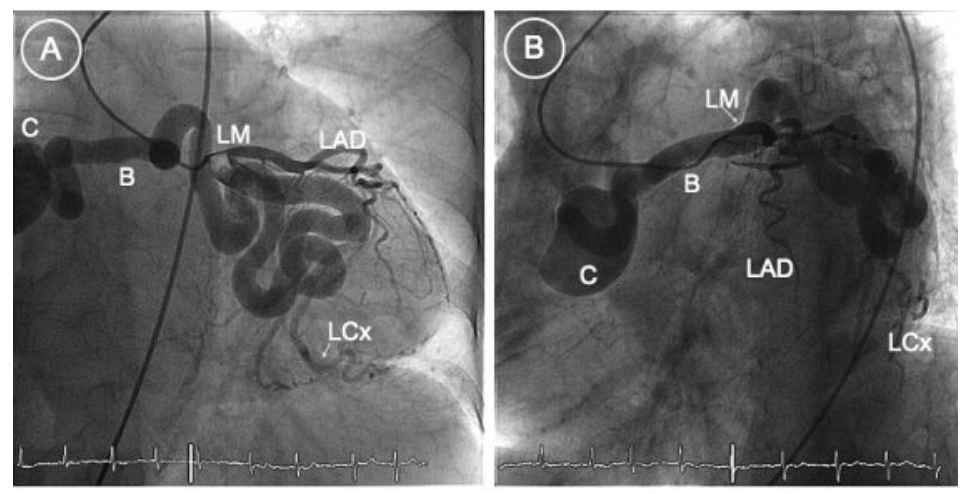

\section{Figure 2}

RAO (A) and anteroposterior (B) caudal views showing the deployment of coils within the fistula. Successful reduction of bloodflow within the fistula (B). $L M=$ left main coronary artery; $L A D=$ left anterior descending artery; $L C X=$ left circumflex artery.
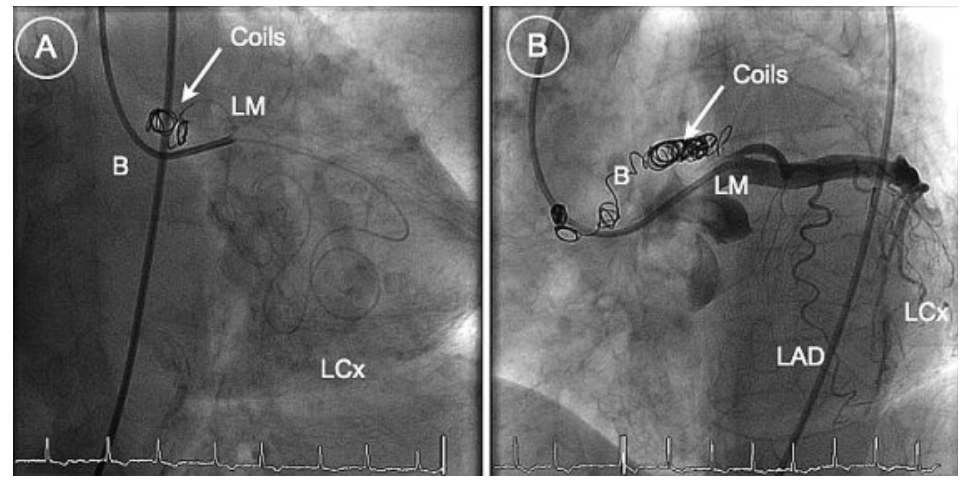

The authors certify that there is no actual or potential conflict of interest in relation to this article. to admission by orthopnoea and nycturia. Typical chest pain with no radiation had started a few hours before admission. There were no cardiac risk factors and vital signs were normal. Physical examination revealed a holo-systolic murmur with axillary radiation, diffuse pulmonary rales associated with expiratory wheezing and bilateral inferior hypoventilation. Minimal peripheral oedema was present but no jugular vein distension. Chest X-ray was highly suggestive of acute pulmonary oedema. Laboratory investigations revealed leucocytosis at $32.8 \mathrm{G} / \mathrm{l}$ consistent with the patient's history of chronic lymphoblastic leukaemia, blood BNP was elevated at $177 \mathrm{pg} / \mathrm{ml}$ and the rest of the initial workup including cardiac enzymes was normal. The ECG showed atrial fibrillation at $60 \mathrm{bpm}$, the rest being unremarkable.

The initial transthoracic echocardiography revealed both severe mitral and tricuspid regurgitation with bilateral atrial dilation and pulmonary artery hypertension estimated at $55 \mathrm{~mm} \mathrm{Hg}$. The left ventricular ejection fraction was normal. Under medical therapy (metoprolol, lisinopril and torasemide), the symptoms receded and the mitral regurgitation drastically diminished. A coronary angiogram was performed to rule out an ischaemic origin for the valvular disease. The latter revealed a giant coronary fistula arising from the mid circumflex coronary artery to the right atrium (fig. 1). A left-to-right shunt was estimated by Fick's method (Qp/Qs 1.6) and the mitral regurgitation was graded as trivial.

It was considered that the symptoms were at least in part triggered by the coronary fistula. A 6 Fr EBU 4.0 guiding catheter was therefore used to selectively engage the left main stem. The fistula was cannulated

Correspondence:

PD Dr Stéphane Cook

Cardiologie invasive

Hôpital Cantonal de Fribourg

$\mathrm{CH}-1700$ Fribourg

Switzerland

Stephanecook@mac.com 


\section{Figure 3}

Anteroposterior view. End result after deployment of 5 coils.

$\mathrm{LM}=$ left main coronary artery; $L A D=$ left

anterior descending artery; $L C X=$ left circumflex artery.

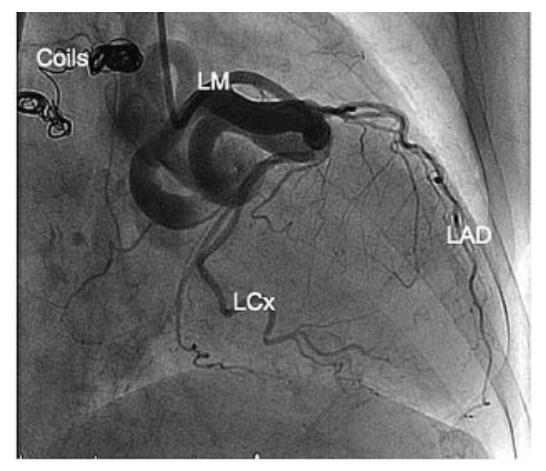

with a Fathom (Boston Sci) steerable guidewire (0.016"). Using a Renegade STC 18 microcatheter, and five 2D Interlock coils (Boston Sci; $10 \mathrm{~mm} \times 30 \mathrm{~cm}, 4 \times$ $8 \mathrm{~mm} \times 20 \mathrm{~cm}$ ) were deployed within the fistula and successfully clogged the visible blood flow within it (fig. $2 \mathrm{~B}$ and 3 ). There were no periprocedural complications and the patient was discharged the following day with a lifelong prescription of aspirin. The risk of atrial fibrillation-related ischaemic stroke was mild (CHADs score of 1 point $-2.8 \%$ /year) but - mainly due to the patient's age - the risk of bleeding was high (CRUSADE bleeding risk was 54 points - 14\%/month). Therefore, and in order to allow complete and definitive closure of the fistula, oral anticoagulation was discontinued for one month. Three months post procedure the patient remained free of symptoms.

\section{Discussion}

Although rare, coronary artery fistulas remain the most common congenital coronary artery defect. They may arise from anywhere along the coronary vessels and drain to any cardiac chamber, great veins or pulmonary arteries; most, however, originate from the right coronary and $90 \%$ drain into the right side of the circulation [1]. Although the incidence is unknown, as much as $75 \%$ of the fistulas could remain clinically silent [2]. Coronary steal syndromes manifesting as angina are amongst the common complications and have been reported even with small fistulas [3]. Other complications are thrombosis, embolism, cardiac failure, atrial fibrillation, haemopericardium due to rupture, endocarditis and arrythmias. Large fistulas can result in non-restrictive shunts, which may lead to volume overload and ventricular dysfunction [4].

Our working hypothesis was that the coronary steal decreased antegrade blood flow in the distal part of the circumflex artery and provoked ischemia with angina pectoris and papillary muscle dysfunction with secondary mitral regurgitation. Such conditions have been described in two previous case reports [5-6].

Percutaneous closure of the fistula is simple and has rapidly superseded surgery as the treatment of choice, unless patients present with other conditions requiring surgery such as other congenital anomalies.

\section{References}

1 Liberthson RR. Congenital anomalies of coronary arteries. In Gatzoulis MA, Webb GD, Daubeney PEF (eds.) Diagnosis and management of adult congenital heart disease. Edinburgh, Churchill Livingstone, 2003, pp 425-32.

2 Latson LA. Coronary artery fistulas: how to manage them. Catheter Cardiovascular Interv. 2007;70(1):110-6.

3 Skimming JW, Walls JT. Congenital coronary fistula suggesting a 'steal phenomenon' in a neonate. Pediatric Cardiology. 1993;14:174-5.

4 Khurana R, Mittal T, Qasim A, Malik I, Qureshi SA, Bogers AJ. EuroIntervention. 2009;4(4):542-8.

5 Ahmed J, Edelstein Y, Rose M, Lichstein E, Connolly MW. Coronary arteriovenous fistula with papillary muscle rupture. South Med J. 2000;93(6):627-8

6 Said SA, Austermann-Kaper T, Bucx JJ. Congenital coronary arteriovenous fistula associated with atrioventricular valvular regurgitation in an octogenarian. Int J Cardiol. 1993;38(1):96-7. 